\title{
Juventude, escola pública e grupos de jovens carismáticos: as reformas educacionais da gestão federal (2016-2018) e a socialização juvenil
}

\author{
Youth, public school and charismatic youth groups: the educational of the federal
} administration (2016-2018) and the youth socialization

\author{
Fabio Lanza* \\ Douglas Alexandre Boschini**
}

\begin{abstract}
Resumo
O presente artigo reflete acerca dos espaços socializadores ocupados pelos jovens, em especial as escolas públicas e os grupos de jovens do movimento da Renovação Carismática Católica. Tendo em vista o papel fundamental da escola, tanto no processo de transmissão e reprodução da estrutura social vigente, faz-se mais que necessárias a atenção e a compreensão das reformas promovidas pelo atual governo (2016-2018) na Política Pública de Educação, bem como, as ações desenvolvidas pelas organizações religiosas enquanto instituições com grande poder educacional junto ao respectivo público. Ainda, o trabalho foi embasado em pesquisas bibliográfica, eletrônica e documental, além de observações de campo realizada em encontros de grupos de oração da RCC. Concluiu-se que a educação pública sendo sucateada pela gestão federal atual, acrescido pelo descrédito e o desrespeito generalizados à ciência e aos educadores, favorecendo aos grupos de jovens religiosos da RCC, oferecem não somente o pertencimento, identificação e o acolhimento, que deveria também ocorrer na escola pública, mas uma série de conteúdos, sob o prisma religioso individualista-conservador, que explicam a realidade e suas relações com a sociedade brasileira.
\end{abstract}

Palavras-chave: Reforma do ensino médio. Lei no 13.415/2017. Sociologia das religiões. Juventude carismática.

\begin{abstract}
This article reflects on the socializing spaces occupied by youngsters, especially the public schools and the Charismatic Catholic Renewal. Considering the fundamental role of the school, both in the process of transmission and the reproduction of the current social structure, the attention and understanding of the reforms promoted by the current government (2016-2018) in Public Education Policy as well as the actions developed by religious organizations as institutions with great educational power with the respective public. This article was based on bibliographical, electronic and documentary research, as well as field observations from meetings of the CCR prayer groups. We conclude that public education being scrapped by the federal administration current, added by the disrepute and widespread disrespect to science and educators, in favor of the CCR youth groups, offering not only the belonging, identification and welcome, which should also occur in the public school, but a series of contents, under the individualist-conservative religious prism, that explain reality and its relations with Brazil's society.
\end{abstract}

Keywords: High school reform. Act no 13.415/2017. Sociology of religion. Charismatic youth.

\footnotetext{
* Doutor em Ciências Sociais, Professor Associado do Departamento de Ciências Sociais e Programa de PósGraduação em Ciências Sociais da Universidade Estadual de Londrina/UEL-PR. E-mail: lanza1975@gmail.com.

** Doutorando do Programa de Pós-Graduação em Serviço Social e Política Social da Universidade Estadual de Londrina, bolsista da Fundação Araucária, Mestre em Ciências Sociais e pesquisador do Laboratório de Estudos sobre Religiões e Religiosidade LERR da Universidade Estadual de Londrina/PR.
} 


\section{Introdução}

Há certo tempo a juventude enquanto categoria vem se solidificando na qualidade de objeto de pesquisas no meio acadêmico, com o avanço tecnológico ocorrido nas últimas décadas os marcos geracionais que definiam as diferentes gerações estão se aproximando cada vez mais, também, a flexibilidade e a pluralidade existentes nos processos definidores das identidades vividos pelos jovens os tornam sujeitos de pesquisa atrativos aos olhos dos pesquisadores das mais diferentes áreas do conhecimento.

Não são somente os estudos científicos têm dedicado maior atenção aos jovens, esta é uma ação que vem sendo tomada também pelos Estados, mais especificamente no Brasil a partir do início do século XXI uma série de políticas públicas e de programas foram desenvolvidos com o foco na juventude.

A juventude ${ }^{1}$ também não passa desapercebida pelas instituições religiosas, que encontram nessa parcela da população um campo fértil para a reprodução de seus fiéis e para o exercício proselitista vinculado à disputa e conquista de novos públicos para os púlpitos. No meio católico romano, após a abertura dada pelo Concílio Vaticano II (1962-1964), diversos movimentos surgiram no interior da Igreja, sendo a Renovação Carismática Católica um dos que mais se destaca no Brasil. Este movimento, tipicamente leigo, registra desde seu início forte participação dos fiéis mais jovens, desenvolvendo ao longo dos anos uma forte aceitação dos mesmos.

Em uma realidade social complexa como a brasileira, para a maioria da população trabalhadora, a RCC por meio de seus Grupos de Oração oferta aos jovens espaços de socialização com pares onde os mesmos se sentem reconhecidos e ouvidos, em meio à aceleração da urbanização no Brasil e as diversas transformações sociais, os espaços tipicamente ocupados pela juventude foram alterados, as incertezas políticas e econômicas não deixam de marcar a realidade dos jovens no Brasil do século XXI.

Tendo em vista este cenário, o presente artigo propõe um debate acerca dos espaços socializadores ocupados pelos jovens, em especial as escolas públicas, por meio de uma discussão sobre as Políticas de Estado e suas reformas no último biênio 2016-2018, e o movimento da Renovação Carismática Católica. Assim, foi analisado como a crise política

\footnotetext{
${ }^{1} \mathrm{O}$ uso do termo juventude não exclui ou deixa de reconhecer que no campo dos estudos acadêmicos muito tem se produzido e debatido sobre a pluralidade e diversidade que compõe o estrato social dos jovens, por isso, explana-se que existem muitas abordagens teóricas que tratam o respectivo estrato pelo uso do termo: juventudes.
} 
acelerada pela tomada golpista do Estado pelo atual presidente ${ }^{2}$ e os desmontes e ataques à educação afetam os processos formadores da juventude brasileira. $\mathrm{O}$ trabalho foi embasado em pesquisas bibliográfica, eletrônica e documental, além de observações de campo realizada em encontros de quatro grupos de oração da RCC localizados em bairros das zonas, Norte, Sul, Leste e Oeste do município de Londrina no ano de 2014 pelo período de seis meses ${ }^{3}$.

A Renovação Carismática Católica, desde seu nascimento, tem contado com a presença do público jovem entre seus fiéis, seu surgimento ocorreu em um retiro espiritual promovido por docentes e estudantes da Universidade de Duquesne no ano de 1967 nos Estados Unidos da América. Portanto, a participação da juventude se caracteriza enquanto forte característica deste movimento, desde sua chegada ao Brasil em 1969 com a vinda dos padres jesuítas, Haroldo Rahm e Eduardo Dougherty, na cidade de Campinas, interior do estado de São Paulo, suas ações se focam em especial no público jovem, sendo que seus eventos são idealizados com o intuito de atrair e agradar fiéis desta faixa etária.

O enfoque na população jovem não se apresenta enquanto característica exclusiva da Renovação Carismática Católica, em denominações neopentecostais e pentecostais também são encontradas atividades e grupos com apelo à juventude, um exemplo deste fato é a Jornada Mundial da Juventude, sediada pelo Brasil no ano de 2013, que apesar de ser um evento católico, diversos grupos jovens de denominações pentecostais e neopentecostais estiveram presentes.

$\mathrm{O}$ apelo à juventude pode ser facilmente compreendido ao se pensar na diminuição do contingente de fiéis, se tratando os de uma nova geração de adeptos, priorizar essa camada da população de certa forma consiste em uma estratégia de sobrevivência da Igreja Católica, assim como uma tentativa de frear o esvaziamento das fileiras de fiéis dos bancos das suas paróquias.

Contudo, é mais do que necessário compreender quais são as relações estabelecidas com a juventude e, principalmente, quais os conteúdos transmitidos, pois, se entende neste trabalho os grupos de jovens religiosos enquanto instituições com grande poder educacional. Em via de regra, no Brasil, as denominações religiosas são um dos primeiros espaços, além da família, de socialização - ação entendida aqui enquanto processo educacional das normas e

\footnotetext{
2 Para maior aprofundamento sobre o golpe jurídico parlamentar ver entrevista com o Professor Boaventura de Souza Santos (BOAVENTURA..., 2016).

${ }^{3}$ Neste artigo não serão trazidas as informações empíricas específicas da pesquisa de campo, mas as mesmas encontram-se disponíveis em Boschini (2014).
} 
estruturas da sociedade -, portanto, ao se refletir sobre as relações entre a Igreja Católica e a Juventude brasileira, pensa-se quais os conteúdos transmitidos aos jovens e quais os impactos dos mesmos para a sociedade, já que todos os códigos apreendidos nas igrejas não se limitam as suas paredes, sendo levados e gerando ações ao universo extra religioso.

Para serem melhores trabalhadas as relações da Renovação Carismática Católica com os jovens, torna-se importante realizar um debate a respeito de juventude e movimentos religiosos, uma vez que este público alvo tem mostrado grande potencial no que se refere à adesão e ou permanência dos adeptos no campo católico. Primeiramente, faz-se necessário delimitar ao que se refere quando denominado juventude.

\footnotetext{
E quem são "eles"? São aqueles nascidos há 14 ou 24 anos - seria uma resposta. No entanto, esses limites de idade também não são fixos. Para os que não têm direito à infância, a juventude começa mais cedo. $E$, no outro extremo - com o aumento de expectativas de vida e as mudanças no mercado de trabalho -, uma parte "deles" acaba por alargar o chamado "tempo da juventude" até a casa dos 30 anos. Com efeito, qualquer que seja a faixa etária estabelecida, jovens com idades iguais vivem juventudes desiguais (NOVAES, 2006, p. 105).
}

Delimitar uma faixa etária para classificar a juventude apresenta-se enquanto uma difícil tarefa, sendo mutável e flexível dependendo de qual juventude está sendo abordada. Portanto, para realizar tal tarefa, neste trabalho são utilizadas as definições legais, que segundo o Estatuto da Juventude (Lei 12.852/13), em seu artigo 1ํ, parágrafo 1으, considera jovem, a pessoa com idade entre 15 e 29 anos (BRASIL, 2013). A concepção legal que delimita a juventude não deve em momento algum excluir a questão abordada por Novaes (2006), entretanto permite, de forma pontual, não somente um recorte etário para o conceito, mas também, uma delimitação de qual público está sendo visado quando se fala de Políticas Públicas de Juventude.

\section{Juventude, políticas públicas e os emergentes retrocessos brasileiros (2016-2017)}

Atualmente a juventude tem se tornado alvo de diversas pesquisas que visam estudar como esse grupo social relaciona-se na e com a sociedade. Durante muito tempo os jovens foram considerados questionadores da sociedade, assim como potenciais atores de mudança social, tendo em vista as concepções que sempre relacionam a juventude com rebeldia. Entretanto, em um outro olhar, este grupo pode, também, ser relacionado com a reprodução de modelos sociais. 
Para Groppo (2000), a juventude possui caráter de agente transformador da ordem social em oposição aos adultos que apresentam maior resistência às mudanças, uma vez que já apresentam posturas e concepções formadas a respeito das realidades, enquanto os jovens encontram-se em um espaço de experimentação e formulação de opiniões.

De certo modo é possível afirmar que os jovens estão em uma posição intermediária na sociedade, já superaram a infância, recebendo maiores responsabilidades, liberdades, ao mesmo tempo não são considerados adultos, mas são cobrados atitudes e comportamentos similares, portanto pode-se pensar a juventude enquanto uma fase de transição. É justamente neste espaço intermediário que são criadas e recriadas as culturas jovens, fazendo emergir signos de reconhecimento e de identidades.

Entretanto, em uma sociedade plural não é possível encontrar uma identidade homogênea que caracterize a juventude, tendo em vista tal fato, pesquisadores que abordam questões a respeito deste grupo social têm utilizado do conceito de "tribos urbanas"4. Além deste conceito, diversos outros são utilizados para abordar a diversidade existente entre os jovens, entretanto, independente dos conceitos ou linhas teóricas utilizadas, vários autores apontam para a formação de grupos juvenis, sejam punks ou religiosos.

Independentemente da identidade dos grupos juvenis, é fato que a juventude se encontra em um constante processo de elaboração de valores e concepções para interpretar o mundo, sendo que os ideais dos grupos aos que pertencem possuem elementos formadores de opinião.

\begin{abstract}
A fome, o amor, o trabalho, a religiosidade, a técnica, as funções sociais ou os resultados da inteligência não são em seu sentido imediato, por si sós, sociais. São fatores da sociação apenas quando transformam a mera agregação isolada dos indivíduos em determinadas formas de estar com o outro e de ser para o outro que pertencem ao conceito geral de interação [...] (SIMMEL, 2006, p. 60).
\end{abstract}

A importância de conhecimento a respeito dos grupos apresenta-se justamente no fato destes exercerem grande influência na vida dos jovens, ideias em comum aproximam os jovens fazendo-os organizarem-se em grupos, mas em momento algum é possível afirmar que todas as ideias e ideais são igualmente compartilhados por todos integrantes, entretanto o pertencimento, assim como a vontade de pertencer, produz códigos e normas de

\footnotetext{
${ }^{4}$ Termo cunhado inicialmente pelo sociólogo Michel Maffesoli (1998), sendo difundido com a publicação de seu livro, O tempo das tribos: o declínio do individualismo nas sociedades de massa.
} 
comportamento, que orientam ações, ao mesmo tempo em que delimitam uma identidade coletiva.

A formação de grupos caracteriza-se enquanto importante elemento para a compreensão a respeito das juventudes e de seus comportamentos, sendo que suas características estão diretamente vinculadas à própria sociedade.

\begin{abstract}
Para entender as mudanças ocorridas no perfil da juventude nos últimos anos, é necessário compreender as mudanças da própria sociedade brasileira, principalmente no que tange a questão educacional, trabalhista e política. Parte-se do pressuposto que os espaços privilegiados pela juventude para participação na sociedade foram mudando conforme o desenvolvimento histórico, sendo que nos anos 1960 e 1970 havia o predomínio do sindicato e movimento estudantil, nos anos 1980 nos movimentos sociais e nos anos 1990 os jovens atuam de forma diluída e fragmentada nos movimentos culturais e lúdicos (SOFIATI, 2008, p. 3-4).
\end{abstract}

No trecho acima citado, Sofiati aponta a direta relação entre as transformações sociais e as alterações nos perfis das juventudes, dando destaque mais específico para as mudanças nos campos: educacional, trabalhista e político. Tais áreas produzem grande impacto na construção das juventudes uma vez que se constituem em espaços que produzem efeitos tanto na realidade contemporânea quanto nas possibilidades de perspectivas futuras. Sendo assim, o desenvolvimento de políticas públicas voltadas para a juventude, demonstram a necessidade reconhecida pelo governo de desenhar uma nova geração, reconhecer a juventude enquanto grupo social passível de intervenção via Estado é reconhecer que esta camada, de acordo com Rua (1998) negligenciada, especialmente na América Latina, não só possui demandas emergentes, mas também, é através do atendimento, hoje, deste público que se torna possível produzir transformações futuras.

No ano de 2006, um ano após a criação da Secretaria Nacional da Juventude, foi publicado o Guia de políticas públicas de juventude (BRASIL, 2006), onde foram listados e apresentados os 20 principais programas do Governo Federal para a Juventude, sendo eles: Projeto Agente Jovem; Programa Bolsa Atleta; Programa Brasil Alfabetizado; Programa Escola Aberta; Programa Escola de Fábrica; Programa de Melhoria e Expansão do Ensino Médio; Programa Juventude e Meio Ambiente; Programa Nossa Primeira Terra; Programa Cultura Viva; Programa de Integração de Educação Profissional ao Ensino Médio na Modalidade de Educação de Jovens e Adultos; Programa Nacional de Estímulo ao Primeiro Emprego; Programa Nacional de Inclusão de Jovens; Programa Nacional do Livro Didático para o Ensino 
Médio; Projeto Rondon; Programa Pronaf Jovens; Programa Universidade para Todos; Programa Saberes da Terra; Programa Segundo Tempo; Projeto Soldado Cidadão.

Dentre todos os programas acima listados, muitos não chegaram a ser postos em prática nacionalmente, entretanto, vale ressaltar a questão de que dos 20 programas, 10 deles estavam sobre a responsabilidade do Ministério da Educação, fato que demonstra claramente, não só o reconhecimento do alcance numérico da Educação - já que os 14 anos da Educação Básica, Infantil, Fundamente e Ensino Médio, são obrigatórios -, mas também de seu papel fundamental no processo socializador dos indivíduos, pois é dentro do alcance escolar que os jovens aprendem os códigos de apreensão do mundo assim como as normas e as estruturas sociais.

Nos anos iniciais do século XXI, fica evidente uma maior intervenção do Estado via políticas públicas, em especial por meio de políticas sociais de redistribuição de renda. No tocante à Educação, o Brasil apresentou avanços, tanto na Educação Básica, pela obrigatoriedade desde 2009 de 14 anos de educação pública e gratuita, quanto no Ensino Superior pelos programas de expansão das Universidades e Institutos Federais. Mas as políticas não abrangeram somente as ações públicas do Estado, por meio de parcerias públicoprivadas, como os programas, PROUNI, FIES e PRONATEC houve uma articulação que beneficiou as empresas privadas do ramo da educação.

Com a tomada, em 2016, do poder executivo pela atual gestão no governo federal brasileiro, ficou evidente que as ações que buscavam a concretização de direitos e a ampliação da inclusão social foram abandonadas, o congelamento dos investimentos nos chamados gastos públicos por duas décadas ataca diretamente as políticas de Saúde e Educação, sem contar a estrangulação das Políticas Públicas Sociais, que antes mesmo de entrar em vigor tal ação já sentem rigorosamente o desmonte via cortes de verbas, a extinção de secretarias entre outras medidas.

Pensando a juventude, não somente enquanto um grupo social, mas também, como um processo de desenvolvimento do indivíduo, a Educação, aqui referida em sua forma tanto política quanto institucional, apresenta um papel determinante no processo socializador dos jovens. É por meio das Instituições de Ensino que os indivíduos, em tese, apreendem os códigos e os instrumentos de apropriação da cultura e da realidade, sendo então responsabilidade das escolas transmitirem não somente o capital cultural acumulado, mas os meios pelos quais se tornam possíveis as interpretações e apreensões do mundo. 
É válido ressaltar que a clareza da responsabilidade pedagógica do Sistema Educacional não obscurece o papel que o mesmo exerce no processo de legitimação e de manutenção da estrutura social, desigual, em prol das classes dirigentes.

Tendo em vista o papel fundamental da escola, tanto no processo de transmissão e reprodução da estrutura social vigente, quanto na possibilidade de produção de um desvio, faz-se mais que necessárias a atenção e a compreensão das reformas promovidas pelo atual governo na Política de Educação.

Na obra A economia das trocas simbólicas, Pierre Bourdieu (2004) analisa o Sistema Educacional como responsável pela transmissão dos instrumentos de apropriação da cultura. A Escola ao não transmitir de forma rigorosa tais instrumentos, relegando à família, tende a agir em prol do monopólio das classes capazes de realizar essa transmissão por seus próprios meios, sendo assim, não são os bens simbólicos propriamente ditos que são distribuídos desigualmente, mas sim os instrumentos de apropriação.

A reprodução de um sistema desigual de distribuição de capital cultural entre as classes gera impactos objetivos na vida dos jovens, em meio a um sistema de manutenção da desigualdade as relações desenvolvidas entre os estudantes e o Sistema de Ensino são construídas com base no grau de identificação dos sujeitos com os conteúdos e os espaços, sendo assim, a valorização ou desvalorização da escola, a sensação de pertencimento e até a evasão, são de certa forma uma antecipação das possibilidades determinadas para as classes.

É justamente com base nessa análise que se torna mais visível as intenções e os objetivos das reformas - ou dos ataques - promovidas na educação brasileira.

Em geral, quando o enfoque da Política Pública Educacional em modalidades de ensino, Técnico e Profissionalizante, fica demonstrado o que Bourdieu (2004) aponta como uma antecipação, há determinação para o jovem os possíveis espaços que estarão disponíveis a ele, tendo em vista constante, a classe que se origina.

As reflexões sobre a proposta acima indicam que as análises das Políticas Públicas e de seus projetos revelam não somente suas projeções objetivas, mas também, suas compreensões e valorações acerca dos sujeitos por elas atendidos e atingidos. Em especial, ao pensar sobre as Políticas Públicas destinadas à juventude tem que se alcançar as significações dadas a essa parcela da população e, se tratando de sujeitos em fase de transição é necessário que compreender quais os objetivos visados a serem alcançados quando estes forem reconhecidos enquanto adultos. Em suma, quando se estudam as reformas que 
atingem os jovens, tem que pensá-las enquanto uma etapa, onde o resultado real será atingido posteriormente ao término desta fase.

Ainda sob a perspectiva da agenda nacional, na atualidade sobre o recorte Política Pública Educacional e a juventude brasileira, selecionou-se de forma intencional o documento publicado pelo Ministério da Educação e aprovado pelo Conselho Nacional de Educação em dezembro de $2017^{5}$, a Base Nacional Curricular Comum. A BNCC (BRASIL, 2018) constitui o documento mais atual e que serve, enquanto referência nacional dos conhecimentos indispensáveis, aos estudantes da Educação Básica, ou seja, levando em consideração a enorme diversidade da população e das regiões do Brasil que gera a necessidade de adaptação, entre as escolas brasileiras, prevista pela Lei de Diretrizes e Bases de 1996, vem apresentar uma série de conteúdos que devem ser padronizados na Educação, visando diminuir a desigualdade educacional presente no Brasil.

A BNCC (BRASIL, 2018) já era debatida por especialistas da área há alguns anos, entretanto, a versão apresentada pelo MEC e aprovada no Conselho Nacional de Educação excluiu todo o material e o processo realizados nos anos anteriores.

A Reforma do Ensino Médio, imposta pela Lei 13415/2017, propõe a inclusão da modalidade do Ensino Profissionalizante como uma escolha a ser tomada pelos jovens quando realizarem suas respectivas matrículas. No entanto, trata-se de um projeto político, que por fim, poderá impor a maior parte dos municípios brasileiros restrições porque não terá a oferta de todas as modalidades previstas na legislação, por meio dos itinerários formativos, de acordo com sua redação:

Art. 36. O currículo do ensino médio será composto pela Base Nacional Comum Curricular e por itinerários formativos, que deverão ser organizados por meio da oferta de diferentes arranjos curriculares, conforme a relevância para o contexto local e a possibilidade dos sistemas de ensino, a saber:

I - linguagens e suas tecnologias;

II - matemática e suas tecnologias;

III - ciências da natureza e suas tecnologias;

IV - ciências humanas e sociais aplicadas;

$\checkmark$ - formação técnica e profissional.

$\S 1$ 1ㅇ A organização das áreas de que trata o caput e das respectivas competências e habilidades será feita de acordo com critérios estabelecidos em cada sistema de ensino (BRASIL, 2017).

\footnotetext{
${ }^{5}$ Que visa, dentre outros interesses políticos e econômicos, consolidar a tão questionada Reforma do Ensino Médio produzida pela Lei no 13.415 , de 16 de fevereiro de 2017. Há que se recordar que inúmeras ações do movimento estudantil polemizou e apontou os equívocos da respectiva reforma, dentre elas, as milhares de ocupações das escolas públicas no segundo semestre de 2016. A respectiva lei está disponível em Brasil (2017).
} 
Ao entender que a indicação legal parte da lógica de oferta da Educação Pública para o Ensino Médio "conforme a relevância para o contexto local e a possibilidade dos sistemas de ensino" (BRASIL, 2017), acabará por enfatizar e naturalizar as diferenças sociais e econômicas dos estudantes. Aqui, parece que, o que se pretende de fato é determinar mais fortemente na educação básica qual o alcance e quais as perspectivas para os estudantes de acordo com suas classes sociais, é definir o mais cedo possível até onde cada jovem pode chegar de acordo com sua origem e as restritas possibilidades impostos pelo seu contexto e limites dos sistemas de ensino organizados em sua cidade.

As medidas adotadas e de certa forma outorgadas pelo então Presidente desde a tomada do governo, em 2016, correspondem aos interesses diretos não somente de parte da classe dirigente da sociedade brasileira, mas também das demandas dos organismos internacionais ou dos ditames do mercado ${ }^{6}$. No entanto, elas vêm sendo recebidas pela maior parte da população, de forma geral, como ações positivas e necessárias para modernização da educação e da possibilidade de ocupação do mercado de trabalho pelos jovens.

A aceitação, ou em certos casos o apoio, aos desmontes e às reformas promovidas pelo governo na área da Educação, correspondem a um problema maior e anterior a atual gestão federal iniciada em 2016. Várias hipóteses poderiam responder à questão da apatia de grande parte da sociedade brasileira com relação ao campo da Educação: 1) no Brasil as instituições escolares públicas de forma geral vêm passando por um processo de desvalorização contínuo; 2) as instituições educacionais (públicas ou privadas) não conseguem garantir um sucesso financeiro por meio da sua respectiva formação e pelo diploma outorgado ao seu egresso; 3) pela ampla campanha promovida pelos setores reacionários e conservadores que visam promover o descrédito dos profissionais da educação e da própria ciência, por exemplo, apoiadores dos projetos de Lei "Escola Sem Partido" em todo país.

As ações em prol da ampliação e da democratização da Educação realizadas nos primeiros anos do século XXI vieram acompanhadas de uma reação de igual ou maior força contrária ao projeto democratizante da educação, ao mesmo tempo em que foram ampliados os sistemas de cotas e criados os Institutos Federais, as empresas privadas de educação cresceram em maior proporção, ampliando os conflitos no campo da Educação.

\footnotetext{
${ }^{6}$ Para maior aprofundamento, ver entrevista do pesquisador Allan Kenji Seki da UFSC concedia a André Antunes (2018).
} 
O fato é que as Políticas Públicas, desde que ousaram olhar minimamente para as camadas mais exploradas da população a partir da gestão do Partido dos Trabalhadores em 2003, mesmo de mãos dadas aos setores econômicos privados acabaram se tornando alvo em um centro de conflitos onde os discursos de ódio e os preconceitos mais diversos imperam. São reações tradicionalistas que vislumbram projetos políticos conservadores e buscam barrar os avanços ou motivar retrocessos. A Reforma do Ensino Médio (2017) não só tentou inovar e modernizar, mas suprimiu a obrigatoriedade de disciplinas como Sociologia e Filosofia, dentre outras. Aspecto que expressa um retrocesso de mais de 20 anos na história do Brasil, é como se voltasse num possível túnel do tempo para os idos do último quarto do século XX, quando as respectivas disciplinas não eram obrigatórias e não compunha a grade curricular da Educação Básica.

\section{Jovens brasileiros e a socialização religiosa}

Neste contexto do século XXI sob o prisma das reformas da Educação Básica, a partir de 2016, é que se amplia a preocupação com os jovens brasileiros, haja visto que os dados indicados pela ONU - agência Brasil a partir do relatório da OIT apresentam que:

[...] a região da América Latina e Caribe deve registrar o maior aumento das taxas de desemprego entre jovens no mundo, segundo relatório divulgado na segunda-feira (20) pela Organização Internacional do Trabalho (OIT). As perspectivas regionais são negativamente afetadas pelo fraco desempenho econômico do Brasil, onde a taxa de desemprego entre jovens deve atingir 30\%, o maior índice desde 1991, segundo o documento "Tendências Globais de Emprego para a Juventude 2017" (OIT..., 2017).

Ao se considerar a partir do exposto que as políticas públicas para o campo da Educação no Brasil não privilegiam os interesses de uma formação ampla com qualidade para os jovens e que atenda ao mercado de trabalho, percebe-se que similarmente não incorpora a respectiva mão de obra, permitindo na atualidade o maior índice de desemprego juvenil desde 1991. Destarte, torna-se mais do que necessária a análise dos espaços de socialização ocupados pelos jovens, mais especificamente neste trabalho, os espaços religiosos.

Tendo em vista o processo de desvalorização da Educação e dos possíveis descrédito à ciência e os seus quadros profissionais, os jovens estão encontrando em outros espaços os conteúdos e ou códigos necessários para interpretação do mundo e, como já citado, as instituições religiosas são aqui compreendidas enquanto instituições educadoras. 
A Igreja Católica sempre manteve uma relação muito estreita com a Educação, foi ela responsável no período colonial pela Educação formal no Brasil, mas mesmo após a separação entre o Estado e a Igreja, com a proclamação da República em 1889 e, a criação de um sistema público de educação a Igreja Católica manteve suas ações no campo educacional por meio de suas escolas confessionais privadas. Contudo, o que se debate aqui neste trabalho é mais precisamente o processo formador que ocorre dentro dos muros das paróquias e os seus grupos de jovens vinculados à Renovação Carismática Católica, porque tem se apresentado enquanto espaço de socialização para a juventude.

Segundo pesquisa realizada pelo instituto Bertelsmann Stiftung no ano de 2007, intitulada "Monitor religioso", o Brasil estava reconhecido enquanto o 20 país mais religioso do mundo, estimando que $96 \%$ da população declara-se religiosa, e ainda, é considerado o 3o país com maior número de jovens religiosos ${ }^{7}$, sendo que $30 \%$ dos jovens se dizem religiosos e 65\% se dizem profundamente religiosos (BERTELSMANN STIFTUNG, 2007). Também, em 2011 a Fundação Getúlio Vargas publicou os resultados de uma pesquisa intitulada "Novo mapa das religiões", sob coordenação de Marcelo Cortês Neri, onde o Brasil está posto como o país com maior contingente de católicos, com um número estimado em 68,43\% da população em 2009, o que correspondia ao equivalente de 130 milhões de brasileiros (NERI, 2011). O IBGE (2012) atualizou os dados sobre a população católica, que apesar de permanecer o movimento das últimas décadas de redução proporcional frente às demais denominações, ainda é majoritária e perfaz $64,6 \%$ da população nacional.

Ao se analisar estes dados, torna-se clara a importância reconhecida às religiões no Brasil, assim como, a juventude brasileira tem sido atraída para os movimentos religiosos. Vale ressaltar que as religiões se apresentam enquanto instituições formadoras, uma vez que são compostas por dogmas, ideais e concepções, que são constantemente ensinados e repassados aos seus seguidores. É a partir do reconhecimento deste fato que se propõe um debate a respeito dos meios pelos quais a RCC promove uma aproximação com a juventude, ao mesmo tempo quais os conteúdos apreendidos pelos mesmos, uma vez que estes jovens transitam por espaços extra religiosos, levando consigo seus ideais.

A Renovação Carismática Católica trouxe, para o catolicismo brasileiro, diversas novas propostas de prática e atuação da Igreja, que viriam a modificar definitivamente as

\footnotetext{
${ }^{7}$ Sendo precedido pela Nigéria com $100 \%$ e Guatemala com 97\%.
} 
formas de suas ações. Consigo vieram, também, novos espaços para a evangelização, como estratégia de proselitismo.

Se apresenta enquanto uma grande característica deste movimento, a alta participação dos fiéis, sendo que "tem se mostrado como um movimento leigo e independente em relação à estrutura da Igreja" (PRANDI, 1998, p. 52). Apesar de constituirse, até certo ponto, enquanto um movimento autônomo, produzido por fiéis, um de seus projetos envolve diretamente a estrutura da própria Igreja, como aponta Prandi (1998) a Renovação Carismática Católica apresenta ações de dupla reação, pois é:

[...] primeiro, um movimento mais geral, voltado para fora do catolicismo, isto é, tendo como oposição o pentecostalismo e outras religiões que vem minando as fileiras católicas. Segundo, um movimento voltado para dentro da própria Igreja, enfraquecendo as posições assumidas pela Igreja Católica da Teologia da Libertação e das CEBs, comprometida com transformações sociais à esquerda [...] (PRANDI, 1998, p. 1).

Portanto, a RCC além de exercer esforço para recuperar o contingente de fiéis perdidos devido ao forte trânsito religioso, esse movimento também atua no sentido de promover alterações estruturais na Igreja Católica. Sendo estas alterações percebidas a partir da própria participação dos leigos, o que acabou por resultar em uma alteração na estrutura hierárquica católica, uma vez que se reconhece não somente maior espaço de atuação, mas também de reconhecimento e força.

Dentre as transformações trazidas pela Renovação Carismática Católica, não há como negar que os Grupos de Oração - seu principal espaço de atuação - apresentam-se enquanto uma das mudanças mais radicais na Igreja, considerando que antes o papel evangelizador era reconhecido aos padres e os mesmos ficavam responsáveis pela organização das atividades de sua paróquia. Já com a RCC, os Grupos de Oração são coordenados e executados por lideranças religiosas leigas, ou seja, pelos fiéis, que se tornaram responsáveis por evangelizar nestes espaços e organizar tanto os debates quanto as atividades.

Neste ponto faz-se necessário ressaltar, que apesar de os Grupos de Oração serem promovidos pelos fiéis, todos os assuntos neste espaço debatidos estão diretamente ligados ao pensamento religioso católico, permitindo aos párocos fiscalizarem e sugerirem os conteúdos abordados.

A importância dos Grupos de Oração no funcionamento da Renovação Carismática Católica transcende ao poder de agregação dos mesmos. Nos Grupos é que são decididas as 
atividades que serão realizadas, como festas, encontros etc., portanto, agem também, enquanto mediadores e conectores com os demais grupos de oração.

Conforme mencionado, a RCC trouxe uma série de transformações e práticas para a Igreja Católica, que tem atraído a participação da camada jovem dos fiéis. A seguir serão trabalhadas algumas das principais mudanças promovidas por este movimento.

O novo conjunto de práticas, rituais e espaços utilizados pela RCC que modernizaram as formas de atuação da Igreja, têm por objetivo principal a ampliação de seu projeto evangelizador. Visto que são utilizados como ferramentas com o intuito de atrair novos fiéis e agradar o seu corpo de praticantes. Portanto, os cenáculos, os grupos de oração, barzinhos de Jesus e os demais eventos e práticas religiosas apresentam-se de forma coerente ao projeto modernizador da Renovação Carismática Católica, pautado nas determinações e orientações do Concílio Vaticano II, demonstrando o interesse deste movimento pela juventude.

Torna-se válido ressaltar que a maior parte das atividades promovidas pela Renovação Carismática Católica são idealizadas com o intuito de aproximar este movimento de seus fiéis, em especial os jovens. Sejam em encontros, festas, músicas, livros ou programas de televisão, seus conteúdos possuem uma linguagem jovial, sendo a própria utilização dos mesmos, focada nas práticas e nos espaços cotidianos da juventude.

Independente do meio utilizado a RCC está constantemente repassando os dogmas católicos, suas músicas abordam temas a respeito da devoção a Deus, castidade, assim como seus livros, os debates realizados nos grupos de oração e outros, os ideais católicos estão sendo constantemente difundidos para seus fiéis, influenciando diretamente em suas vidas em especial em seus relacionamentos com os outros indivíduos.

Em A economia das trocas simbólicas, Pierre Bourdieu (2004) afirma que o processo de formação de instituições religiosas está diretamente relacionado à produção de um capital religioso:

\footnotetext{
O processo conducente à constituição de instâncias especificamente organizadas com vistas à produção, à reprodução e à difusão dos bens religiosos, bem como a evolução [...] do sistema destas instâncias no sentido de uma estrutura mais diferenciada e mais complexa, ou seja, em direção a um campo religioso relativamente autônomo, se fazem acompanhar por um processo de sistematização e de moralização das práticas e das representações religiosas [...] (BOURDIEU, 2004, p. 37, grifo do autor).
}

Sendo assim, as instituições religiosas em sua formação e constituição passam por um processo de sistematização de normas, práticas e conhecimentos, os quais compõe o 
capital religioso das mesmas. Considerando a pluralidade de denominações existentes no campo religioso brasileiro é de fácil percepção que existam semelhanças e até similaridades nas práticas, normas e conhecimentos das religiões. Aspectos que acabam por gerar uma disputa na busca por legitimação de suas doutrinas as instituições religiosas caracterizandoas enquanto rivais, uma vez que lutam pelo mesmo público, envolvendo-as em conflitos, na tentativa de validar seus ideais ao deslegitimar os demais.

\footnotetext{
Essa simbólica de poder religioso instiga nos adeptos do Pentecostalismo Autônomo uma suposta superioridade espiritual que justifica quaisquer formas de autodefesa, assim como o ataque indiscriminado contra todos os possíveis adversários ou concorrentes [...] (BITTENCOURT FILHO, 2003, p. 202).
}

Ainda que Bittencourt Filho no trecho acima refira-se ao Pentecostalismo Autônomo, a posição de defesa e ataque é facilmente reconhecida na Renovação Carismática Católica, que na tentativa que promover-se, e assegurar a sua manutenção, define seus inimigos e transfere-os para seus fiéis. Sendo assim, no campo religioso os inimigos estão caracterizados como qualquer religião que possa oferecer o risco de criar um trânsito religioso e, assim, diminuir o contingente de fiéis praticantes da Renovação Carismática Católica.

Como foi trabalhado, a RCC tem empreendido esforços de atuação no mercado editorial com grande sucesso. Dentre os conteúdos dos livros publicados pelas editoras da RCC ou ligadas ao movimento estão apostilas, cursos de formação, materiais de estudo e aprofundamento espiritual, os quais abordam questões acerca da espiritualidade e normas de conduta.

Por meio de pesquisa documental, foi identificado que o Conselho Nacional da Renovação Carismática Católica foi lançado no início dos anos de 1990 uma coleção intitulada Ofensiva Nacional, com o intuito de esclarecer e difundir suas práticas e ideias.

Em outra fonte documental carismática, o livro intitulado Perguntas e respostas sobre a fé de autoria do Padre Alberto Luiz Gambarini (1990), o autor apresenta elementos do catolicismo em uma tentativa de invalidar as críticas destinadas à Igreja Católica a respeito do batismo, utilização de imagens entre outras, ao mesmo tempo em que explana a respeito de outras instituições religiosas.

Considerando que a Renovação Carismática Católica consiste em um movimento leigo e seu público alvo é composto, em especial, pela juventude católica, questões a respeito de seus conteúdos e suas crenças tornam-se de extrema importância. Uma vez que seus 
jovens integram uma camada populacional ativa que será lançada ao mercado de trabalho e diversos outros espaços sociais, em que carregarão todo o conhecimento apreendido neste movimento. Sendo assim, o conhecimento a respeito de como questões referentes à castidade, sexualidade e à pluralidade religiosa tornam-se fundamentais, já que estes conteúdos se apresentam de forma elementar na formação de pensamentos que transcendem a questões religiosas.

Entretanto, ao serem analisadas as opiniões oficiais da RCC a respeito dos assuntos acima citados, é de fácil percepção que este movimento demonstra uma postura muito tradicionalista e até retrógrada, ao mesmo tempo em que se apresenta enquanto reformador que, segundo Oliveira et al. (1978, p. 72) na realidade se consiste em "um movimento muito menos renovador do que pretende ser". Propõe-se uma reforma nas estruturas cotidiana e de atuação leiga dentro da Igreja Católica, mas caracteriza-se em um movimento voltado aos estudos bíblicos e às orações, sua tendência é de estimular o individualismo e suas as perspectivas espiritualistas, faz com que reforce a caracterização de um movimento conservador.

A RCC e os seus jovens estão inseridos em um contexto de alto trânsito religioso e em um cenário de grande pluralidade religiosa, é de fácil percepção a sua postura defensiva e agressiva em relação às demais denominações religiosas como as pentecostais/neopentecostais e as não-cristãs, principalmente as afro-brasileiras, dentre outras.

Como já foi dito, a Renovação Carismática Católica não nega esforços na promoção de eventos com grande apelo juvenil, onde suas crenças são constantemente trabalhadas e massificadas a seus fiéis, sendo assim, esta pesquisa procurou compreender quais as razões que levam a juventude, que em diversos aspectos é vista enquanto questionadora e até como força motriz de mudanças sociais, a filiar-se a um movimento pautado na tradição católica com projetos políticos reacionários e intolerante com as diferentes identidades religiosas.

\section{Considerações finais}

As questões acima destacadas demonstram a abrangência do pensamento religioso difundido aos jovens, como já foi trabalhado, a juventude integrante dos grupos de oração não compartimenta sua vida dividindo o religioso e o laico, os conteúdo, os dogmas e os ideais 
apreendidos nos movimentos religiosos são, não só levados ao meio público, como aplicados, produzindo efeitos mesmo naqueles que não compartilham de tais ideias.

As posições de oposição, repulsa e até mesmo a postura de combate vista em muitos jovens em relação a termos públicos, como por exemplo os referentes ao direito reprodutivo da mulher, são compreendidos quando analisado que esses jovens estão sendo socializados em espaços onde tais ideias são condenadas e também onde se é proposta uma ação de luta, que delimita muito bem que os inimigos são todos aqueles contrários ao seu pensamento oriundo da matriz religiosa católica e carismática.

Os jovens buscam e deveriam encontrar nas escolas, local privilegiado dos serviços da Política Pública de Educação, um espaço de conhecimento que Ihes oferecesse os meios necessários para a compreensão do mundo. Onde fossem ouvidos e reconhecidos enquanto sujeitos. Entretanto, com a realidade atual, o sucateamento e os constantes ataques por parte do governo, o descrédito e o desrespeito generalizados à ciência e aos funcionários da educação, esse mesmo jovem já não se reconhece mais enquanto pertencente àquele espaço. Esse aspecto é reforçado ao se associar as milhares de Ocupações das Escolas Públicas, realizadas pelos estudantes secundaristas em 2016, quando se posicionaram contra aquela Reforma do Ensino Médio e por seguinte, o Governo Federal promulga sua respectiva implementação no formato da Lei no 13.415 de 16 de fevereiro de 2017.

Dessa forma, parte da juventude brasileira encontra nas organizações religiosas certa valorização e atenção; a partir dos estudos os espaços e os grupos de jovens religiosos da RCC, não produzem somente o pertencimento, identificação e o acolhimento, que deveria também ocorrer na escola pública, mas uma série de conteúdos, sob o prisma religioso individualistaconservador, que explicam a realidade e suas relações com a sociedade brasileira.

\section{Referências}

ANTUNES, André. 'Em termos de educação pública nunca experimentamos um inimigo com uma força social tão concentrada como esse'. In: FIOCRUZ. Escola Politécnica de Saúde Joaquim Venâncio. Rio de Janeiro, 11 maio 2018. Disponível em: http://www.epsjv.fiocruz.br/noticias/entrevista/em-termos-de-educacao-publica-nuncaexperimentamos-um-inimigo-com-uma-forca. Acesso em: 30 maio 2018.

BERTELSMANN STIFTUNG. Religionsmonitor. Gütersloh, 2007. Disponível em: http://www.religionsmonitor.com/index.php?lang=ES. Acesso em: 14 maio 2013.

BITTENCOURT FILHO, José. Matriz religiosa brasileira: religiosidade e mudança social. Petrópolis: Vozes, 2003. 
BOAVENTURA: contra o golpe parlamentar no Brasil. In: BOITEMPO EDITORIAL. Blog da Boitempo. São Paulo, 2 jun. 2016. Disponível em:

https://blogdaboitempo.com.br/2016/06/02/boaventura-contra-o-golpe-parlamentar-nobrasil/. Acesso em: 30 maio 2018

BOSCHINI, Douglas Alexandre. Renovação Carismática Católica em Londrina/PR: a juventude dos grupos de oração. 2014. Dissertação (Mestrado em Ciências Sociais) - Universidade Estadual de Londrina, Londrina, 2014.

BOURDIEU, Pierre. A economia das trocas simbólicas. 5. ed. São Paulo: Perspectiva, 2004.

BRASIL. Guia de políticas públicas da juventude. Brasília: Secretaria-Geral da Presidência da República, 2006.

BRASIL. Lei no 12.852, de 5 de agosto de 2013. Institui o Estatuto da Juventude e dispõe sobre os direitos dos jovens, os princípios e diretrizes das políticas públicas de juventude e o Sistema Nacional de Juventude - SINAJUVE. Brasília: Presidência da República, 2013. Disponível em: http://www.planalto.gov.br/CCIVIL_03/_Ato20112014/2013/Lei/L12852.htm. Acesso em: 30 maio 2018.

BRASIL. Lei no 13.145, de 16 de fevereiro de 2017. Altera as Leis nos 9.394, de 20 de dezembro de 1996, que estabelece as diretrizes e bases da educação nacional, e 11.494, de 20 de junho 2007, que regulamenta o Fundo de Manutenção e Desenvolvimento da Educação Básica e de Valorização dos Profissionais da Educação, a Consolidação das Leis do Trabalho - CLT, aprovada pelo Decreto-Lei no 5.452, de 10 de maio de 1943, e o Decreto-Lei no 236, de 28 de fevereiro de 1967; revoga a Lei no 11.161, de 5 de agosto de 2005; e institui a Política de Fomento à Implementação de Escolas de Ensino Médio em Tempo Integral. Brasília: Presidência da República, 2017. Disponível em: http://www.planalto.gov.br/ccivil_03/_ato2015-2018/2017/lei/L13415.htm. Acesso em: 30 maio 2018.

BRASIL. Ministério da Educação. Base Nacional Comum Curricular. Brasília: Ministério da Educação, 2018. Disponível em: http://basenacionalcomum.mec.gov.br/images/BNCC_EI_EF_110518_versaofinal_site.pdf. Acesso em: 30 maio 2018.

GAMBARINI, Alberto Luiz. Perguntas e respostas sobre a fé. 6. ed. São Paulo: Edições Loyola, 1990.

GROPPO, Luís Antônio. Juventude: ensaios sobre sociologia e histórias das juventudes modernas. Rio de Janeiro: Difel, 2000.

IBGE. Censo 2010: número de católicos cai e aumenta o de evangélicos, espíritas e sem religião. Rio de Janeiro, 29 jun. 2012. Disponível em: https://censo2010.ibge.gov.br/noticiascenso.html?view=noticia\&id=1\&idnoticia $=2170 \&$ busca $=1 \& \mathrm{t}=$ censo-2010-numero-catolicos cai-aumenta-evangelicos-espiritas-sem-religiao. Acesso em: 7 jan. 2018.

MAFFESOLI, Michel. O tempo das tribos: o declínio do individualismo nas sociedades de massa. Rio de Janeiro: Forense Universitária, 1998. 
NERI, Marcelo Côrtes (coord.). Novo mapa das religiões. Rio de Janeiro: FGV, 2011. Disponível em: http://www.cps.fgv.br/cps/bd/rel3/REN_texto_FGV_CPS_Neri.pdf. Acesso em: 14 maio 2013.

NOVAES, Regina. Os jovens de hoje: contextos, diferenças e trajetórias. In: ALMEIDA, Maria Isabel Mendes de; EUGENIO, Fernanda (org.). Culturas jovens: novos mapas do afeto. Rio de Janeiro: Jorge Zahar, 2006. p. 105-120.

OIT: desemprego entre jovens brasileiros deve atingir 30\% em 2017, maior taxa desde 1991. In: UNIC RIO. Nações Unidas Brasil. Rio de Janeiro, 21 nov. 2017. Disponível em:

https://nacoesunidas.org/oit-desemprego-entre-jovens-brasileiros-deve-atingir-30-em2017-maior-taxa-desde-1991/. Acesso em: 5 jan. 2018.

OLIVEIRA, Pedro de Assis Ribeiro de; BOFF, Leonardo; LIBÂNIO, João Batista; BETTENCOURT, Estevão. Renovação Carismática Católica: uma análise sociológica e interpretações teológicas. Petrópolis: Vozes, 1978.

PRANDI, Reginaldo. Um sopro do espírito. São Paulo: Fapesp, 1998.

RUA, Maria das Graças. As políticas públicas e a juventude dos anos 90. In: RUA, Maria das Graças. Jovens acontecendo na trilha das políticas públicas. Brasília: CNPD, 1998. v. 2, p. 731 752.

SIMMEL, George. Questões fundamentais da sociologia: indivíduo e sociedade. Rio de Janeiro: Jorge Zahar, 2006.

SOFIATI, Flávio Munhoz. A juventude no Brasil: história e organização. Passages de Paris, Paris, n. 3, maio 2008. 